\title{
Disentangling a complex nationwide Salmonella Dublin outbreak associated with raw-milk cheese consumption, France, 2015 to 2016
}

Aymeric Ung ${ }^{1,2,3}$, Amrish Y. Baidjoe ${ }^{3,4,5}$, Dieter Van Cauteren ${ }^{1}$, Nizar Fawal5, Laetitia Fabre5, Caroline Guerrisi ${ }^{6}$, Kostas Danis $^{1,2}$,

Anne Morand ${ }^{7}$, Marie-Pierre Donguy7, Etienne Lucas ${ }^{1}$, Louise Rossignol${ }^{6}$, Sophie Lefèvre ${ }^{5}$, Marie-Léone Vignaud ${ }^{8}$, Sabrina CadelSix ${ }^{8}$, Renaud Lailler ${ }^{8}$, Nathalie Jourdan-Da Silva ${ }^{1,9}$, Simon Le Hello ${ }^{5,9}$

1. Santé publique France (SpFrance), the French national public health agency, Saint-Maurice, France

2. European Programme for Intervention Epidemiology Training (EPIET), European Centre of Disease Prevention and Control (ECDC), Stockholm, Sweden

3. These authors contributed equally to this article and share first authorship

4. European Programme for Public Health Microbiology Training (EUPHEM), European Centre of Disease Prevention and Control (ECDC), Stockholm, Sweden

5. Institut Pasteur, Enteric Bacterial Pathogens Unit, National Reference Center (NRC) for E. coli, Shigella and Salmonella, Paris, France

6. Sorbonne Université, UPMC, INSERM, Institut Pierre Louis d'épidémiologie et de Santé Publique, IPLESP, Paris, France

7. French Directorate General for Food (DGAL), Ministry of Agriculture and Food, Paris, France

8. Université Paris-Est, French Agency for Food, Environmental and Occupational Health and Safety (ANSES), Laboratory for Food Safety, Maisons-Alfort, France

9. These authors contributed equally to this article and share last authorship

Correspondence: Nathalie Jourdan-da Silva (nathalie.jourdan-dasilva@santepubliquefrance.fr)

On 18 January 2016, the French National Reference Centre for Salmonella reported to Santé publique France an excess of Salmonella enterica serotype Dublin (S. Dublin) infections. We investigated to identify the source of infection and implement control measures. Whole genome sequencing (WGS) and multilocus variable-number tandem repeat analysis (MLVA) were performed to identify microbiological clusters and links among cases, animal and food sources. Clusters were defined as isolates with less than 15 single nucleotide polymorphisms determined by WGS and/or with identical MLVA pattern. We compared different clusters of cases with other cases (case-case study) and controls recruited from a web-based cohort (case-control study) in terms of food consumption. We interviewed $63 / 83$ (76\%) cases; 2,914 controls completed a questionnaire. Both studies' findings indicated that successive $S$. Dublin outbreaks from different sources had occurred between November 2015 and March 2016. In the case-control study, cases of distinct WGS clusters were more likely to have consumed Morbier (adjusted odds ratio (aOR): 14; 95\% confidence interval (Cl): 4.842) or Vacherin Mont d'Or (aOR: 27; 95\% Cl: 6.8-105), two bovine raw-milk cheeses. Based on these results, the Ministry of Agriculture launched a reinforced control plan for processing plants of raw-milk cheeses in the production region, to prevent future outbreaks.

\section{Background}

Nontyphoidal Salmonella is a main cause of bacterial food-borne infection in Europe $[1,2]$. The majority of human infections is caused by a limited number of Salmonella serotypes among the 2,600 described to date [3,4]. Salmonella enterica serotype Dublin (S. Dublin) is particularly invasive in humans and more often leads to severe disease and higher mortality rates compared with other serotypes [4-7]. S. Dublin is host-adapted to bovines and is frequently isolated from cattle, with raw milk or raw-milk cheeses as a typical vehicle for food-borne outbreaks [8,9]. In 2012, a major $S$. Dublin outbreak occurred in France, with 103 cases linked to Saint-Nectaire (bovine raw-milk cheese) consumption $[10,11]$. In 2015, 34 S. Dublin cases were reported linked to the consumption of Reblochon (bovine raw-milk cheese) (data not shown; Santé publique France).

In France, the National Reference Center for Salmonella (NRC) and the French Agency for Food, Environmental and Occupational Health and Safety (ANSES) routinely collect and serotype human and non-human Salmonella isolates, respectively [12-14], using the Kauffmann-White-Le Minor scheme [3]. The S. Dublin isolates collected are frequently susceptible to all antibiotics and show an indistinguishable pulsed-field gel electrophoresis 


\section{FIGURE 1}

Flowchart of human and non-human Salmonella Dublin isolates ${ }^{\mathrm{a}}$ subtyped and included in the study, France, 2015-2016 (n =289)

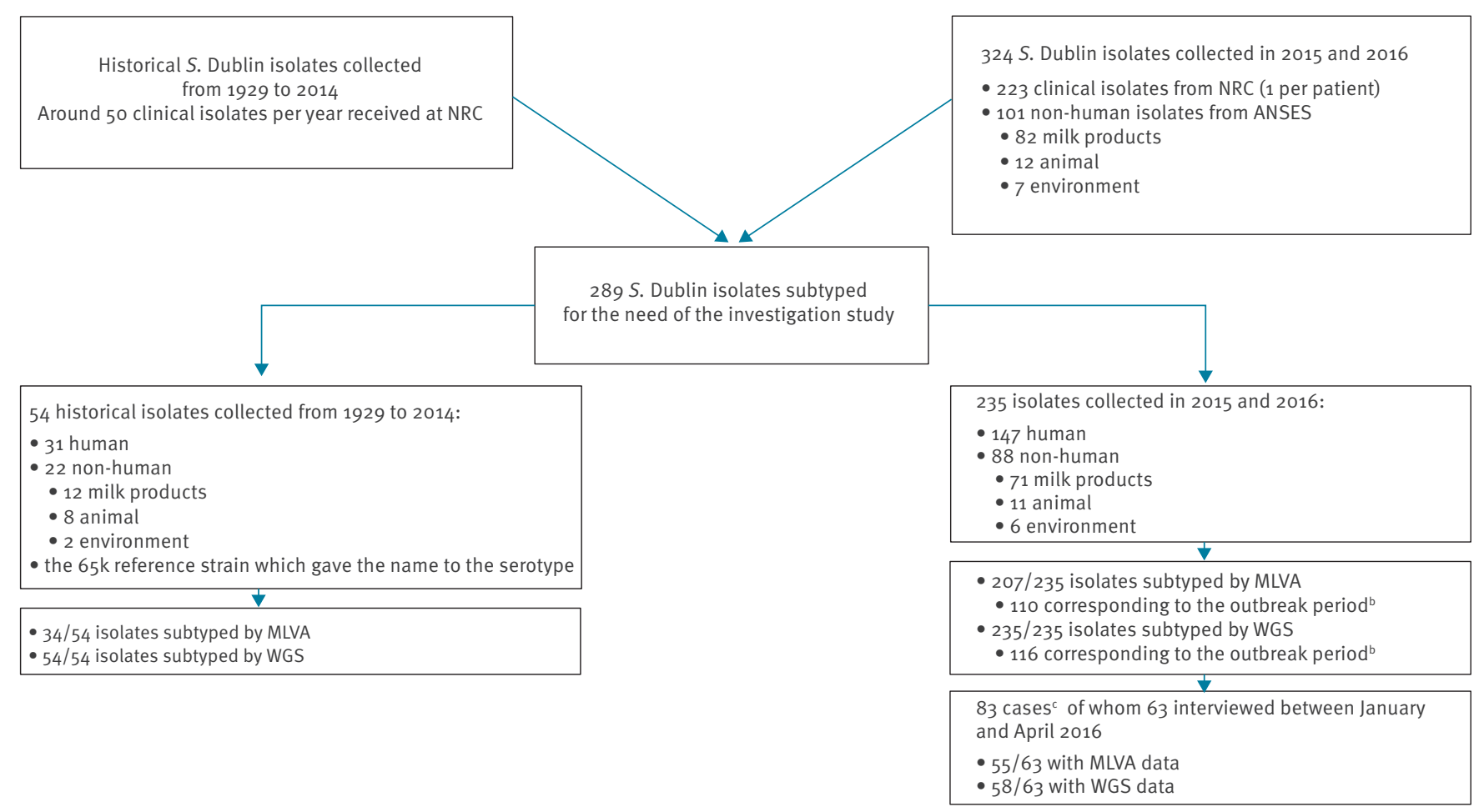

ANSES: French Agency for Food, Environmental and Occupational Health and Safety; MLVA: multilocus variable-number tandem repeat analysis; NRC: national reference center; WGS: whole genome sequencing.

a While the study was conducted between 2015 and 2016, the subtyped isolates also included historical strains isolated between 1929 and 2014 .

b The outbreak period is from 17 November 2015 to 11 March 2016.

'Case definition: residents in mainland France with a S. Dublin infection reported to the NRC between 17 November 2015 and 11 March 2016.

(PFGE) pattern. To better distinguish S. Dublin isolates, multilocus variable-number tandem repeat analysis (MLVA) has recently been used for surveillance and outbreak investigations $[11,15]$. Moreover, whole genome sequencing (WGS) of Salmonella has been shown to discriminate between closely related isolates of $S$. Dublin $[16,17]$.

\section{Outbreak detection}

On 18 January 2016, the French NRC reported to Santé publique France (SpFrance, the French national public health agency) an excess of $S$. Dublin infections across the country, with $37 \mathrm{~S}$. Dublin isolates identified between mid-November 2015 and mid-January 2016, compared with $10 \mathrm{~S}$. Dublin isolates during the same period in the two previous years. An outbreak investigation team with experts from SpFrance, NRC, ANSES and the French Directorate General for Food (DGAL) launched extensive epidemiological, microbiological and food investigations to confirm the outbreak, identify the vehicle of transmission and propose appropriate control measures.

\section{Methods}

We carried out both epidemiological and microbiological investigations on subsets of $S$. Dublin cases and isolates, respectively.

\section{Microbiological investigations}

Salmonella Dublin isolates

During the years 2015 and 2016, a total of 324 S. Dublin isolates were collected, 223 from clinical NRC isolates (108 in 2015 and 115 in 2016) and 101 from non-human ANSES isolates (62 and 39, in each year respectively). Of those, a total of 235, including 147 (83 in 2015 and 64 in 2016) clinical and 88 (62 and 26, respectively) non-human isolates, were extensively studied by WGS and/or MLVA. We also analysed 54 'historical' subtyped S. Dublin isolates collected between 1929 and 2014, 31 from humans and 22 from non-human specimens, as well as the human isolate which gave the name to the serotype in 1929 (number 65k) [18]. In total, we included 289 isolates in this study (Figure 1 ). 
TABLE 1

Characteristics of Salmonella Dublin outbreak cases, France, November 2015-March 2016 ( $\mathrm{n}=83$, including 63 interviewed cases)

\begin{tabular}{|c|c|c|c|c|}
\hline $\begin{array}{l}\text { Characteristics } \\
\text { of cases }\end{array}$ & Category & $\mathrm{n}$ & $\mathrm{N}^{\mathrm{a}}$ & $\%$ \\
\hline \multicolumn{5}{|c|}{ All cases $(n=83)$} \\
\hline Sex & Female & 44 & 83 & 53 \\
\hline \multirow{5}{*}{ Age } & $1-17$ & 6 & 83 & 7 \\
\hline & $18-44$ & 10 & 83 & 12 \\
\hline & $45-64$ & 19 & 83 & 23 \\
\hline & $65-84$ & 31 & 83 & 37 \\
\hline & $85-94$ & 17 & 83 & 21 \\
\hline \multirow{9}{*}{$\begin{array}{l}\text { Region of } \\
\text { residence }\end{array}$} & Auvergne-Rhône-Alpes & 8 & 83 & 10 \\
\hline & Bourgogne-Franche-Comté & 19 & 83 & 23 \\
\hline & Bretagne & 6 & 83 & 7 \\
\hline & Grand-Est & 6 & 83 & 7 \\
\hline & Haut-de-France & 7 & 83 & 8 \\
\hline & île-de-France & 9 & 83 & 11 \\
\hline & Nouvelle-Aquitaine & 9 & 83 & 11 \\
\hline & Pays-de-la-Loire & 7 & 83 & 8 \\
\hline & Other $^{\mathrm{b}}$ & 12 & 83 & 15 \\
\hline \multirow{6}{*}{$\begin{array}{l}\text { Type of human } \\
\text { sample }\end{array}$} & Blood & 39 & 83 & 47 \\
\hline & Stool & 25 & 83 & 30 \\
\hline & Urine & 11 & 83 & 13 \\
\hline & Articular fluid & 3 & 83 & 4 \\
\hline & Pus & 2 & 83 & 2 \\
\hline & Other & 3 & 83 & 4 \\
\hline Deceased & Yes $^{c}$ & 10 & 83 & 12 \\
\hline \multicolumn{5}{|c|}{ Interviewed cases $(n=63)$} \\
\hline Comorbidities & Yes $^{d}$ & 39 & 59 & NA \\
\hline \multirow{6}{*}{$\begin{array}{l}\text { Clinical } \\
\text { symptoms }\end{array}$} & Fever $^{f}$ & 38 & 55 & NA \\
\hline & Nausea & 15 & 45 & NA \\
\hline & Vomiting & 19 & 51 & NA \\
\hline & Abdominal pain & 27 & 47 & NA \\
\hline & Diarrhoea & 30 & 56 & NA \\
\hline & Blood in faeces & 5 & 38 & NA \\
\hline Hospitalisation & Yes & 41 & 60 & 68 \\
\hline
\end{tabular}

NA: Not applicable due to low figure in the denominator (<60).

${ }^{a}$ Number of cases for which the information was available.

b Centre Val-de-Loire, Normandie, Occitanie and Provence-AlpesCôte d'Azur.

' Information provided by the National Reference Center for Salmonella (NRC), without confirmation that cause of death was attributable to $S$. Dublin infection.

${ }^{d}$ Asthma, cancer, cardiac problems, diabetes, renal failure.

e Cases could have more than one clinical symptom.

${ }^{f}$ Fever was defined as body temperature $>38^{\circ} \mathrm{C}$ or perception of having fever.

\section{Whole genome sequencing}

The NRC used WGS to subtype all the 289 isolates of which 116 corresponded to the outbreak period from November 2015 to March 2016. High-throughput genome sequencing was carried out at the 'Plateforme de microbiologie mutualisée' ( $\left.P_{2} M\right)$ of the Pasteur International Bioresources network (Institut Pasteur, Paris, France). After extraction with the MagNA Pure 96
System (Roche, Basel, Switzerland), DNA was further processed for sequencing with Illumina systems (libraries using the Nextera XT DNA Library Prep kit and the sequencing with the NextSeq 500 system) generating 100 to $146 \mathrm{bp}$ paired-end reads. Reads were trimmed and assembled as previously described [19]. Genomic data as multilocus sequence typing (MLST) type and resistance genes were detected from assembled sequences using web-tools (http://www.genomicepidemiology.org/). For each isolate, the paired-end reads were aligned against the $S$. Dublin str. 3246 reference genome (GenBank accession number: CMoo1151.1) using Bowtiez with default parameters [20]. A coregenome multi-alignment of assembled genomes was also done using Harvest v1.0.1 f ParSNP function [21]. For each approach, the resulting single nucleotide polymorphisms (SNPS) were concatenated to generate a filtered multiple alignment that was used as input for the construction of a phylogenetic tree using Molecular Evolutionary Genetics Analysis (MEGA)6 [22] with a maximum-likelihood (ML) approach. The final trees were visualised in the interactive Tree Of Life [23]. All reads generated in this study have been deposited in project PRJEB28817.

Multilocus variable-number tandem repeat analysis ANSES used MLVA as described elsewhere [11], to analyse 241 isolates (including 148 human and 93 non-human), of which 110 corresponded to the outbreak period. The measured lengths for each fragment were obtained using an ABI3500 capillary electrophoresis system (Applied Biosystems, France). Data were imported into GeneMapper software (Applied Biosystems, France) where each fragment was identified according to colour and size. A normalisation of the results was done with the free access MLVA Normalizer software [24].

\section{Epidemiological investigation}

\section{Case definition}

We defined cases as residents in mainland France with a $S$. Dublin infection reported to the NRC between 17 November 2015 and 11 March 2016, without travel history outside of France within 7 days prior symptom onset and without history of $S$. Dublin infection before 17 November 2015 (i.e. no S. Dublin strain ever isolated and received at the NRC before 17 November 2015).

\section{Cluster definition}

We defined a cluster as isolate sequences with $<15$ SNP divergence obtained by core-genome comparison and/ or with identical MLVA pattern. Among these clusters, we also defined subclusters as isolate sequences having 5 intra SNPS.

\section{Study design}

We compared cases belonging to a specific cluster/subcluster with other cases belonging to all other clusters/ subclusters in a case-case study and with controls in a case-control study. For the case-control study, 


\section{FIGURE 2}

Number of cases by reported date of onset of symptoms ${ }^{\mathrm{b}}$, Salmonella Dublin outbreak, France, November 2015March $2016\left(\mathrm{n}=83^{\mathrm{b}}\right)$

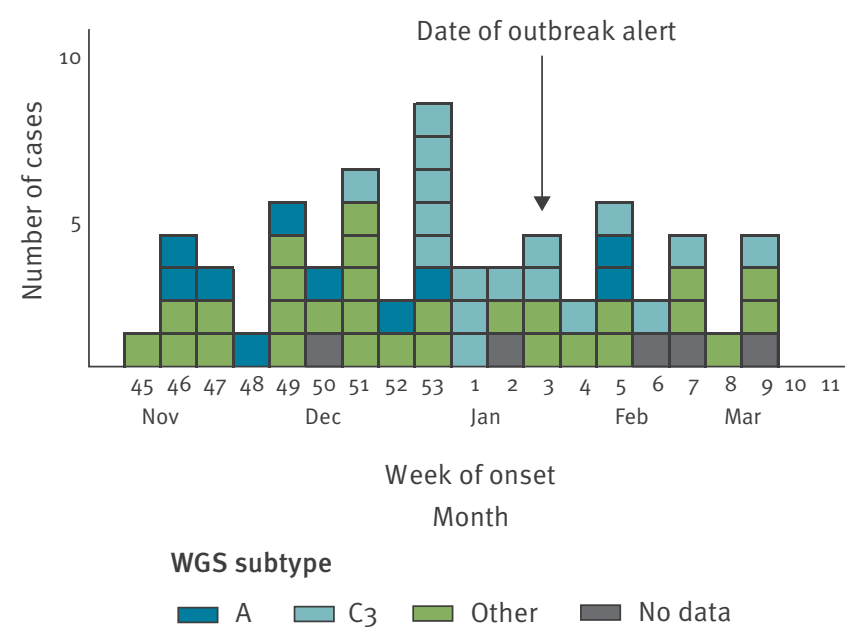

WGS: whole genome sequencing.

${ }^{a} 55$ cases reported a precise day or week of onset and six cases reported a vague period of symptom onset time (within several weeks); we then recorded the last week of that period as the week of onset of symptoms.

${ }^{b}$ For 22 cases, no date of onset was recorded; of these, we did not have a completed questionnaire for 20 .

controls were recruited from a cohort of individuals with children and adults registered on GrippeNet.fr (https:// www.grippenet.fr), an online population-based surveillance system for influenza-like illness $[25,26]$. During winter 2015/16, 6,515 participants reported online the presence or absence of basic symptoms on a weekly basis using a list of 19 predefined symptoms commonly or rarely related to influenza. We excluded controls reporting travel abroad during the Salmonella outbreak period and those with digestive symptoms.

\section{Data collection}

Epidemiologists from the regional offices of SpFrance interviewed the cases by telephone using a trawling questionnaire on clinical symptoms, medical history, detailed food consumption, contact with other persons experiencing diarrhoea, travel history and contact with animals. Loyalty card information was collected to trace-back supermarket purchases.

On week 8 (22-28 February), 2016, controls from the GrippeNet.fr cohort received a web link to complete an online questionnaire about health, travel history and food consumption during 11-17 January 2016 (a 7-day ordinary non-festive period).

\section{Statistical analyses}

We calculated proportions, using the number of nonmissing values as denominators. For the case-case study, we calculated crude odds ratios (OR). For the case-control study, we calculated adjusted odds ratios (aOR) for age and sex using multivariable logistic regression. The initial regression models included age, sex and food items consumed by at least $50 \%$ of the cases. We performed this analysis for WGS clusters/ subclusters and MLVA clusters with at least 10 cases. We used STATA version 12.0 (Stata Corporation, Texas, United States) for this analysis.

\section{Ethical considerations}

The study was approved by the French Commission for Data Protection (Commission Nationale de l'Informatique et des Libertés). Interviewees or next of kin provided verbal consent. Only anonymised data were analysed and used for the purpose of the study.

Food production chain and animal trace-back investigations

DGAL conducted a trace-back investigation on potential contaminated products identified by the epidemiological investigations. Points of purchase, like supermarkets or cheese retailers, were reported by cases. Where possible, customer loyalty card numbers were used to identify the exact point of purchase and product batch numbers and specific production facilities. The traceback investigation was conducted for a retrospective period of up to a month before symptom onset of given cases, if date of onset was available, or if not, up to two months before the date of isolation of $S$. Dublin in the patient specimen. Suspected food products were tested for Salmonella if food samples were available.

\section{Results}

\section{Description of cases}

Between 17 November 2015 and 11 March 2016, 83 cases were identified. Median age was 70 years (range: 1-94), 44 (53\%) were female and respondents originated from $12 / 13$ regions in mainland France, with 19 (23\%) cases coming from the Bourgogne-FrancheComté region (Table 1). S. Dublin was isolated from blood ( $n=39 ; 47 \%)$ but also from stool $(25 ; 30 \%)$, urine (11; $13 \%)$, and other samples $(8 ; 10 \%)$. Ten (12\%) deaths were reported with no information available on the cause of death. Questionnaires were not completed for 20 cases ( 9 deaths, 7 unreachable, 4 refusals), leading to $63(76 \%)$ cases included in further analyses.

Among these cases, 39 of 59 with available information reported having pre-existing chronic medical conditions (asthma, cancer, cardiac problems, diabetes, renal failure). Most frequently reported symptoms included fever (either reported as a measurement of body temperature $>38^{\circ} \mathrm{C}$ or reported as a perception; 38/55), abdominal pain (27/47) and diarrhoea (30/56). Among cases with data on hospitalisation, 68\% (41/60) were hospitalised.

The number of cases peaked during week 53 (28 December-3 January) (Figure 2). 


\section{TABLE 2}

Number of subtyped human and non-human Salmonella Dublin isolates by MLVA patterns (rows) and whole genome sequencing clusters (columns) included in the study, France, 2015-2016 $(\mathrm{n}=289)$

\begin{tabular}{|l|c|c|c|c|c|c|c|c|}
\multirow{2}{*}{ MLVA } & \multicolumn{7}{|c|}{ WGS } & \multirow{2}{*}{ Total } \\
\cline { 2 - 9 } & A & B & $C_{3}$ & $C_{\text {other }}$ & F & K & Other $^{b}$ & \\
\hline $15-8-10-7-5-3$ & 0 & 0 & 0 & 1 & $19^{\mathrm{c}}$ & 0 & 0 & 20 \\
\hline $17-8-10-7-5-4$ & 0 & $9^{\mathrm{d}}$ & 0 & 6 & 0 & 0 & 0 & 15 \\
\hline $18-8-10-7-5-4$ & 0 & $14^{\mathrm{e}}$ & 28 & 3 & 0 & 0 & 2 & 47 \\
\hline $19-8-10-7-5-3$ & 0 & 0 & 0 & $22^{\mathrm{f}}$ & 0 & 0 & 0 & 22 \\
\hline $19-8-10-7-5-4$ & 1 & 4 & 1 & $18^{\mathrm{g}}$ & 0 & 0 & 3 & 27 \\
\hline $20-8-10-7-5-3$ & 0 & 0 & 0 & 10 & 0 & 0 & 0 & 10 \\
\hline $20-8-10-7-5-4$ & 15 & 1 & 0 & 0 & 0 & 0 & 1 & 17 \\
\hline Other & 0 & 5 & 1 & 11 & 15 & 11 & 40 & 83 \\
\hline Missing & 2 & 2 & 5 & 17 & 4 & 0 & 18 & 48 \\
\hline Total & 18 & 35 & 35 & 88 & 38 & 11 & 64 & 289 \\
\hline
\end{tabular}

MLVA: multilocus variable-number tandem repeat analysis; WGS: whole genome sequencing.

a While the study was conducted between 2015 and 2016, the subtyped isolates included historical strains isolated between 1929 and 2014 .

b There were 23 other WGS subtypes.

'Among these 19, 13 were associated with WGS subcluster F4.

${ }^{d}$ All nine isolates with MLVA 17-8-10-7-5-4 pattern were associated with WGS subcluster $\mathrm{B}_{3}$.

e Eight isolates with MLVA 18-8-10-7-5-4 pattern were associated with WGS subcluster B4.

${ }^{f}$ Fourteen isolates with MLVA $19-8-10-7-5-3$ pattern were associated with WGS subcluster C 8 .

${ }^{g}$ Eight isolates with MLVA 19-8-10-7-5-4 pattern were associated with WGS subcluster C6.

${ }^{\mathrm{h}}$ There were 42 other MLVA patterns.

\section{Description of controls}

Among the 6,200 GrippeNet.fr participants (i.e. controls) who could be reached, 2,914 (47\%) completed the questionnaire. Of those, 2,690 (92\%) did this within 2 days; $1,916(66 \%)$ were female; median age was 56 years (range: $2-90$ ). The whole process, i.e. from the beginning of the recruitment of the controls to the end of data collection, took 12 days.

There were significant differences between cases and controls in terms of proportion of female $(53 \%$ in cases vs $66 \%$ in controls; $p$ value $=0.01$ ) and age ( $58 \%$ of cases vs $29 \%$ of controls were 265 years-old; $\mathrm{p}$ value $=0.00$ ).

\section{Microbiological findings}

Among 241 MLVA performed for S. Dublin isolates, 49 different MLVA patterns were obtained and among these, seven gathered 10 or more isolates (Table 2).

The WGS analysis of all the $289 \mathrm{~S}$. Dublin isolates, including historical ones, indicated a unique MLST, ST10 that had previously been related to serotype Dublin in both the literature and public databases (https://enterobase.warwick.ac.uk/) [27]. As the mapping against the $S$. Dublin str. 3246 reference genome
(GenBank accession number: CMoo1151.1) showed high divergence with 19,213 SNPs, the core-genome multialignment of assembled genomes using ParSNP function was preferred. A generated matrix file revealed that maximum divergence for all isolates sequenced during the outbreak including the reference strain was 791 SNPs suggesting a relative homogeneous population of $S$. Dublin isolates that were circulating in France. We identified 28 different clusters with 15 SNPs, including five clusters with $>10$ isolates (clusters $A, B, C, F$ and $\mathrm{K})$. Three of those, A, B and C, accounted for the majority of human $(70 \%, 125 / 179)$ and non-human isolates $(46 \%, 51 / 110)$ (Figure 3).

A total of 18 isolates (17 human and 1 non-human) with date of isolation between October 2015 and March 2016 were identified as belonging to the WGS cluster A and were mainly associated to the MLVA cluster 20-810-7-5-4 (Table 2, Figure 3). In terms of food items, only one WGS cluster A isolate from October 2015 was found in raw milk.

The WGS cluster B comprised a total of 35 isolates (20 human and 15 non-human). Two main subclusters were identified; one $B_{3}$ (mainly associated to the MLVA cluster 17-8-10-7-5-4) was found in relation to cattle, milk and raw-milk cheeses (Reblochon and Morbier) with date of isolation mainly in January 2016 and the other B4 (mainly associated to MLVA cluster 18-8-10-7-5-4) was found in cases with date of isolation mainly in December 2015 and January 2016.

The WGS cluster $C$ was the most prevalent with 123 isolates (88 human and 35 non-human). It was subdivided into nine subclusters ( $<5$ SNPs), $C_{3}$ and $C_{\text {other }}$ (grouping eight smaller subclusters including (8). All the 35 isolates belonging to the $\mathrm{C}_{3}$ subcluster presented a very limited intra SNP difference ( $(2)$ and a sufficient divergence ( $>5$ SNPs) to the other eight $C$ subclusters $\left(C_{\text {other }}\right)$, indicating high level of genetic relationship due to a putative common source of contamination. The WGS subcluster $\mathrm{C}_{3}$ was mainly associated with MLVA cluster 18-8-10-7-5-4 and was found in clinical isolates from patients between January and April 2016. This molecular signature was also found in one isolate from Morbier cheese in February 2016 during this investigation. It was found as well in several isolates in Morbier cheeses tested in 2015 through company internal microbiological monitoring system. The WGS subcluster C8 was mainly associated with the MLVA cluster $19-8-10-7-5-3$ and harboured isolates from patients at the beginning of 2015. In that period, another S. Dublin outbreak had been investigated between February and April 2015 in seven French regions, and was found to be possibly associated with consumption of Reblochon cheese (data not shown; Santé publique France).

Among the non-human isolates, we revealed several other WGS cluster groups (in particular F and K) but no or few linked human isolates (data not shown). The review of the historical human and non-human 


\section{FIGURE 3}

Phylogenetic analysis of all the subtyped human and non-human Salmonella Dublin isolates included in the study that were whole genome sequenced, France, 2015-2016 ${ }^{\mathrm{a}}(\mathrm{n}=289)$
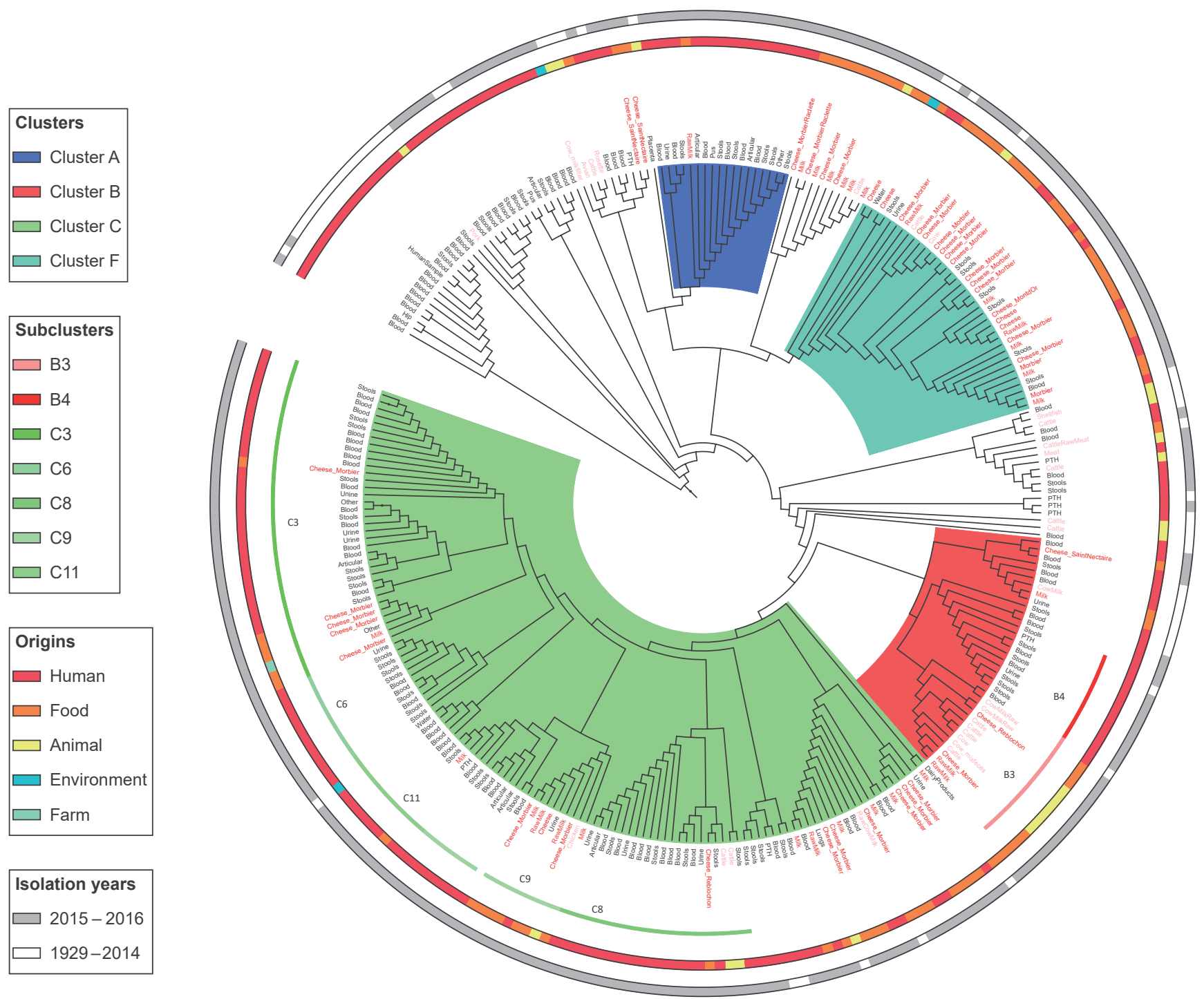

${ }^{a}$ While the study was conducted between 2015 and 2016, the subtyped isolates included historical strains isolated between 1929 and 2014 .

specimens suggested that WGS B and C cluster isolates have been circulating in France for decades, while WGS cluster $A$ isolates seem to be more recent.

Among the 63 cases for whom a completed questionnaire was available, 58 had had an isolate subtyped by WGS, 55 had had an isolate subtyped by MLVA, and 55 both. Of the 58 cases with WGS subtype, 17 belonged to subcluster $\mathrm{C}_{3}, 11$ to cluster $\mathrm{A}$, and 30 to 14 other subclusters. Of the 55 cases with MLVA pattern, 23 belonged to cluster $18-8-10-7-5-4,10$ to cluster $20-8$ 10-7-5-4 and 22 to six other clusters.

\section{Epidemiological investigations}

Case-case study

Compared with cases belonging to the other WGS clusters, WGS cluster A cases seemed to have consumed Vacherin Mont d'Or cheese more frequently, although this result was not statistically significant (odds ratio (OR): 5.1; 95\% confidence interval (CI): 0.9-34). Similarly WGS subcluster $\mathrm{C}_{3}$ cases appeared to be related to Morbier cheese consumption (OR: 3.3; 95\% $\mathrm{Cl}$ : 0.8-15) (Table 3). Compared with cases belonging to other MLVA patterns, MLVA cluster 18-8-10-7-5-4 cases (which frequently coincided with WGS cluster A) seemed to have more often consumed Morbier cheese, however this was not significant (OR: 2.1 ; $95 \% \mathrm{Cl}$ : $0.5-$ 8.3) and MLVA cluster 20-8-10-7-5-4 cases (which 
frequently coincided with WGS cluster $C_{3}$ ) appeared as consuming more often Vacherin Mont d'Or cheese (OR: 5.1; 95\% Cl: 0.9-35). No associations were found with other raw-milk cheeses, nor with any other food items.

\section{Case-control study}

After adjustment for age and sex, compared with controls, cases belonging to the WGS cluster A were more likely to have consumed Vacherin Mont d'Or cheese (aOR: $27 ; 95 \% \mathrm{Cl}: 6.8-105$ ) and cases belonging to the WGS subcluster $\mathrm{C}_{3}$ were more likely to have consumed Morbier cheese (aOR: 14; 95\% Cl: 4.8-42) (Table 3). Compared with controls, cases belonging to the MLVA cluster 18-8-10-7-5-4 were more likely to have consumed Morbier cheese (aOR: $11 ; 95 \% \mathrm{Cl}$ : 4.2-29) and cases belonging to the MLVA cluster 20-8-10-7-5-4 were more likely to have consumed Vacherin Mont d'Or cheese (aOR: $27 ; 95 \% \mathrm{Cl}: 6.8-104)$ ). No other significant associations were found with other raw-milk cheeses, nor with any other food items.

\section{Food trace-back investigations}

We collected 39 (62\%) loyalty card numbers from 63 cases. Based on the available information, trace-back investigations were conducted among 10 supermarket brands. Twelve cheese producers were identified as potential origin of the cheeses consumed by the cases. The trace-back investigations linked one Morbier producer and three different Vacherin Mont d'Or producers, to 11 , five, four and three cases, respectively. All those producers were located in the same region, i.e. Bourgogne-Franche-Comté (Eastern part of France).

\section{Food and veterinary investigations}

From the 101 non-humans isolates collected in 2015 and 2016, 82 (81\%) were collected from milk products (54 from cheese, 27 from milk and one from other dairy), 12 (12\%) from animal samples (cattle, meat, faeces) and seven (7\%) from environmental samples (milk filter, trough). For the 54 cheese samples, S. Dublin was detected in Morbier $(n=37)$, in Saint-Nectaire $(n=6)$, in Reblochon $(n=5)$, in Vacherin Mont d'Or $(n=1)$ and in other or unknown cheeses $(n=5)$.

\section{Discussion}

We reported one of the largest $S$. Dublin outbreaks in France in the past few years. Two different bovine rawmilk cheeses, Morbier and Vacherin Mont d'Or, were the most likely vehicles of transmission for this food-borne outbreak. For the present outbreak investigation we used two different typing methods on a large panel of strains (both historical and obtained during the 201516 outbreak period, as well as from human and nonhuman origins). The first method was MLVA, which had already been used in previous investigations of other outbreaks in France [11]. The second, WGS, was used for the first time in the current $S$. Dublin investigation and demonstrated increased capacity to discriminate clusters. We also used two different epidemiological methods: a case-case study that allowed a rapid analysis and identification of suspected sources and a case-control study that was more statistically powerful to confirm the suspected associations.

In this investigation, MLVA was deemed sufficient to identify a link between human cases, food and animal sources. However, MLVA could not distinguish some of the clusters identified by WGS. Our results suggested that at least two outbreaks of $S$. Dublin occurred during the same period, and potentially originated from two different sources. WGS cluster $A$ and subcluster $C_{3}$ occurred in different periods indicating that they might belong to distinct outbreaks. The retrospective use of WGS also confirmed the occurrence of different S. Dublin outbreaks in $2012[10,11]$. High resolution molecular tools like WGS may facilitate linkage of human cases to sources, especially in serotypes with limited intrinsic genetic variation, and may also provide a more detailed picture of the extent and context of the outbreak.

Recruiting controls from an online health cohort survey for an ongoing outbreak investigation was novel in France and served as a pilot to evaluate the suitability of this method in future food-borne outbreak investigations. This method allowed conducting the case-control study in a timely manner with minimum resources, achieving a high response rate [28].

Our investigation pointed towards several cheese producers from the same region as sources of the outbreaks. In this region, an increase in salmonellosis incidence was observed in cattle at the end of summer 2015 (data not shown; Santé publique France). This could explain the increase of contaminated cheese batches in autumn and winter 2015. Veterinary and food investigations were challenging due to (i) high number of possibly implicated processing plants of raw-milk cheeses, and (ii) the high frequency of cheese consumption by cases and the variety of cheeses and places of purchase. It was difficult to identify the exact batches that cases consumed because some cheeses were sold at the deli counter, sliced on demand. Furthermore, the probable low levels of contamination of the implicated cheeses may have led to false negative test results, possibly allowing some contaminated batches to enter the market.

Previous studies indicated that $S$. Dublin is frequently isolated in live cattle, and that cheeses made with unpasteurised milk may be contaminated with $S$. Dublin $[8,9]$. S. Dublin infection is also responsible for substantial losses in the dairy industry [29]. A modelling exercise in Denmark [29] estimated the gross margin losses due to S.Dublin infection in a 200-cow stall-herd to be up to EUR 188 per stall annually averaged over the 10-year period following introduction of infection. In that study, relative simple and cheap control measures such as improving calving and colostrum management could lead to significant decreases in prevalence of $S$. Dublin in some herds. In other herds, it was reported that these measures might have to 


\section{TABLE 3}

Frequency of reported cheese consumption ${ }^{\mathrm{a}}$ according to MLVA and whole genome sequencing clusters for the case-case study and the case-control study, Salmonella Dublin outbreak, France, November 2015-March 2016 (n cases = 58; n controls $=2,914)$

\begin{tabular}{|c|c|c|c|c|c|c|c|c|c|c|c|c|c|c|c|c|c|c|c|c|}
\hline \multirow{2}{*}{ Type of cheese } & \multicolumn{2}{|c|}{$\begin{array}{l}\text { Cluster } \\
\text { cases }\end{array}$} & \multicolumn{2}{|c|}{$\begin{array}{l}\text { Other } \\
\text { cases }^{b}\end{array}$} & \multicolumn{2}{|c|}{ Controls } & \multicolumn{2}{|c|}{$\begin{array}{l}\text { Case-case } \\
\text { studyc }\end{array}$} & \multicolumn{2}{|c|}{$\begin{array}{l}\text { Case-control } \\
\text { study }^{d}\end{array}$} & \multicolumn{2}{|c|}{$\begin{array}{l}\text { Cluster } \\
\text { cases }\end{array}$} & \multicolumn{2}{|c|}{$\begin{array}{l}\text { Other } \\
\text { cases }^{b}\end{array}$} & \multicolumn{2}{|c|}{ Controls } & \multicolumn{2}{|c|}{$\begin{array}{l}\text { Case-case } \\
\text { study }^{c}\end{array}$} & \multicolumn{2}{|c|}{$\begin{array}{l}\text { Case-control } \\
\text { study }^{\mathrm{d}}\end{array}$} \\
\hline & $\mathrm{n}$ & $\%$ & $\mathrm{n}$ & $\%$ & $\mathrm{n}$ & $\%$ & $\mathrm{OR}$ & $95 \% \mathrm{Cl}$ & $\mathrm{aOR}^{\mathrm{e}}$ & $95 \% \mathrm{Cl}$ & $\mathrm{n}$ & $\%$ & $\mathrm{n}$ & $\%$ & $\mathrm{n}$ & $\%$ & $\mathrm{OR}$ & $\begin{array}{c}95 \% \\
\mathrm{Cl}\end{array}$ & $\mathrm{aOR}^{\mathrm{e}}$ & $95 \% \mathrm{Cl}$ \\
\hline Type of cheese & \multicolumn{10}{|c|}{ MLVA $20-8-10-7-5-4(n=10$ cases $)$} & \multicolumn{10}{|c|}{ WGS A ( $n=11$ cases $)$} \\
\hline $\begin{array}{l}\text { Vacherin Mont } \\
\text { d`Or }^{\text {'O }}\end{array}$ & 7 & 70 & 11 & 31 & 233 & 8 & 5.1 & $0.9-35$ & 27 & $6.8-104$ & 7 & 70 & 12 & 32 & 233 & 8 & 5.1 & $\begin{array}{c}0.9- \\
34\end{array}$ & 27 & $6.8-105$ \\
\hline Comté & 6 & 67 & 21 & 58 & 1,386 & 48 & 1.4 & $0.3-10.2$ & NS & NA & 6 & 67 & 23 & 59 & 1,386 & 48 & 1.4 & $\begin{array}{c}0.2- \\
9.8\end{array}$ & NS & NA \\
\hline Gruyère & 7 & 78 & 26 & 76 & 1,841 & 63 & 1.1 & $0.2-13$ & NS & NA & 7 & 78 & 28 & 78 & 1,841 & 63 & 1.0 & $0.1-12$ & NS & NA \\
\hline Camembert & 6 & 67 & 23 & 66 & 756 & 26 & 1.0 & $0.2-7.6$ & NS & NA & 6 & 67 & 25 & 66 & 756 & 26 & 1.0 & $\begin{array}{c}0.2- \\
7.5\end{array}$ & NS & NA \\
\hline Type of cheese & \multicolumn{10}{|c|}{ MLVA $18-8-10-7-5-4(n=23$ cases $)$} & \multicolumn{10}{|c|}{ WGS C 3 ( $n=17$ cases $)$} \\
\hline Morbier & 12 & 60 & 10 & 42 & 361 & 12 & 2.1 & $0.5-8.3$ & 11 & $4.2-29$ & 10 & 67 & 12 & 37 & 361 & 12 & 3.3 & $0.8-15$ & 14 & $4.8-42$ \\
\hline Goat cheese & 9 & 53 & 13 & 54 & 1,384 & 47 & 1.0 & $0.2-4.0$ & NS & NA & \multicolumn{6}{|c|}{$\begin{array}{l}\text { Not consumed by } 50 \% \text { of the } \\
\text { cases }\end{array}$} & NA & NA & NA & NA \\
\hline Camembert & 12 & 63 & 17 & 68 & 756 & 26 & 0.8 & $0.2-3.4$ & NS & NA & 11 & 73 & 20 & 62 & 756 & 26 & 1.6 & $\begin{array}{c}0.4^{-} \\
8.7^{-}\end{array}$ & NS & NA \\
\hline Gruyère & 13 & 68 & 20 & 83 & 184 & 63 & 0.4 & $0.1-2.3$ & NS & NA & 10 & 71 & 25 & 81 & 184 & 63 & 0.6 & $\begin{array}{l}0.1- \\
3.6\end{array}$ & NS & NA \\
\hline Comté & & & & 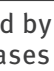 & $\%$ & & NA & NA & NA & NA & 7 & 50 & 22 & 65 & 1,386 & 48 & 0.5 & $\begin{array}{c}0.1- \\
2.3\end{array}$ & NS & NA \\
\hline
\end{tabular}

aOR: adjusted odds ratio; CI: confidence interval; MLVA: Multilocus variable-number tandem repeat analysis; NA: not applicable; NS: did not remain significant in the final logistic regression model; OR: odds ratio; WGS: whole genome sequencing.

a Only cheeses consumed by at least $50 \%$ of the cases are included in the analysis; cases and controls could report more than one cheese consumed.

${ }^{b}$ Cases who belong to the other known subtypes.

'Compares cluster cases with other cases with other known subtypes.

${ }^{d}$ Compares cluster cases with controls.

e Adjusted for age and sex.

be supplemented by changes in hygiene and feeding practices. It might be worthwhile conducting studies in France to evaluate the impact of recent or future measures on $S$. Dublin prevalence at herd level. In addition, infected cattle might carry chronic and possibly asymptomatic infections while still contributing to onwards transmission by excreting pathogens in faeces $[30,31]$. SNP-typing based on WGS is a promising tool to monitor the routes and the spread of $S$. Dublin between herds in traditional regions of cheese production, as already reported in previous studies $[16,17]$. The combination of epidemiological studies in human and nonhuman sectors and the use of WGS may improve the cost effectiveness of control measures for $S$. Dublin in France, by targeting contaminated herds.

Following the investigations currently reported here, the group of producers of Morbier and Vacherin Mont d'Or cheeses implemented an action plan, including (i) systematic testing for Salmonella of batches of Morbier and Vacherin Mont d'Or sold since 1 February 2016, (ii) more regular farm visits by veterinarians, (iii) detection and containment of infected cattle, (iv) expert mission from the Ministry of Agriculture and Food to support milk industry professionals in Bourgogne-Franche-Comté region to identify and recommend better practices for detection and management of contaminated rawmilk products and (v) creation of a working group with experts on Salmonellaissues from different organisations. The Morbier processing plants union reinforced their sanitary protocols, including more frequent testing of milk.

\section{Limitations}

Our investigations suffered from several limitations. First, cases were interviewed by phone, while controls completed a shorter online questionnaire, which could have led to obtaining exposure data with different degrees of accuracy. To minimise this bias, we used the same questions for cases and controls. Second, age and sex distribution of controls differed from that of the cases. We thus included age and sex in the multivariable analysis to adjust for those characteristics. Third, it was difficult to identify the exact sources of contamination due to probably low levels of contamination by $S$. Dublin of the cheese batches. As the cattle contamination was diffuse, it was difficult to incriminate specific cheese producers in the Bourgogne-Franche-Comté region as sources of contamination. Furthermore, suspected batches of 
cheese identified through trace-back investigations were no longer available for testing. Then, even if epidemiological investigations were carried out within a very constrained period of time to allow the ad hoc microbiological analyses to be launched to support the generated hypotheses, we had to deal with the impossibility to get through the whole process due to the lack of products.

\section{Conclusions and recommendations}

Microbiological, epidemiological and environmental evidence pointed towards two raw-milk cheeses, Morbier and Vacherin Mont d'Or, as vehicles of the $S$. Dublin infections. The use of MLVA and WGS subtyping methods allowed the identification of different clusters and of the potential vehicles of infection, highlighting the importance of adequate subtyping methods during Salmonella outbreaks and the relevance of company internal microbiological monitoring system. As a result, WGS has now been routinely implemented at the French NRC and findings of this multi-disciplinary investigation led to a reinforced control plan for processing plants of raw-milk cheeses to prevent future outbreaks.

\section{Acknowledgements}

We are grateful to all the microbiological laboratories processing human and non-human samples, who participate in the Salmonella network for isolates processing. We acknowledge Santé publique France epidemiologists from the regional offices who conducted the interviews, Edith Laurent who performed the data entry and Marie-José Letort who helped contacting laboratories. We thank all the persons involved in the microbiological investigations in Institut Pasteur (in particular Vincent Enouf, Estelle Serre and François Gravey) and in the French Agency for Food, Environmental and Occupational Health and Safety. We also thank the persons who conducted the food trace-back investigations in the Ministry of Agriculture and Food. We are grateful for the persons in the French National Institute of Health and Medical Research in the GrippeNet.fr project who worked with us in implementing the control recruitment method. Finally, we thank all the cases, their relatives and the nursing home staff and the controls who participated in the studies.

\section{Conflict of interest}

None declared.

\section{Authors' contributions}

$\mathrm{AU}, \mathrm{KD}$ and $\mathrm{NJ}$ coordinated the epidemiological part of the investigation. EL implemented the electronic version of the questionnaire, AU was in charge of the case-case study, DVC was in charge of the case-control study. DVC, LR and CG coordinated the part of the investigation regarding the GrippeNet.fr study. MLV, SCS, RL and SLH coordinated the microbiological part of the investigation regarding MLVA: MLV, SCS and RL collected food and animal samples and planned the MLVA analysis of human and non-human isolates, $A B, N F$, $\mathrm{LF}$ and SLH analysed the molecular data, AB, NF, LF, SL and SLH merged and analysed microbiological data, MLV, SCS performed MLVA analyses. AB, NF, LF and SLH coordinated the microbiological part of the investigation regarding WGS.
$A M$ and MPD coordinated the food trace-back part of the investigation. $A U$ and $A B$ took lead in manuscript writing, $N$, $\mathrm{KD}$ and SLH the general coordination. All authors read, commented and approved the final manuscript.

\section{References}

1. Majowicz SE, Musto J, Scallan E, Angulo FJ, Kirk M, O’Brien SJ, et al. International Collaboration on Enteric Disease 'Burden of Illness' Studies. The global burden of nontyphoidal Salmonella gastroenteritis. Clin Infect Dis. 2010;50(6):882-9. https://doi. org/10.1086/650733 PMID: 20158401

2. Langridge GC, Fookes M, Connor TR, Feltwell T, Feasey N, Parsons $\mathrm{BN}$, et al. Patterns of genome evolution that have accompanied host adaptation in Salmonella. Proc Natl Acad Sci USA. 2015;112(3):863-8. https://doi.org/10.1073/ pnas.1416707112 PMID: 25535353

3. Grimont PAD, Weill FX. Antigenic formulae of the Salmonella serovars, 9th ed. Paris: World Health Organization Collaborating Center for Reference and Research on Salmonella, Institut Pasteur; 2007. Available from: https:// www.pasteur.fr/sites/default/files/veng_o.pdf

4. Jones TF, Ingram LA, Cieslak PR, Vugia DJ, Tobin-D’Angelo M, Hurd S, et al. Salmonellosis outcomes differ substantially by serotype. J Infect Dis. 2008;198(1):109-14. https://doi. org/10.1086/588823 PMID: 18462137

5. Helms M, Vastrup P, Gerner-Smidt P, Mølbak K. Short and long term mortality associated with foodborne bacterial gastrointestinal infections: registry based study. BMJ. 2003;326(7385):357. https://doi.org/10.1136/bmj.326.7385.357 PMID: 12586666

6. Mohammed M, Cormican M. Whole genome sequencing provides insights into the genetic determinants of invasiveness in Salmonella Dublin. Epidemiol Infect. 2016;144(11):2430-9. https://doi.org/10.1017/S0950268816000492 PMID: 26996313

7. El Sayed F, Sapriel G, Fawal N, Gruber A, Bauer T, Heym B, et al. In-Host Adaptation of Salmonella enterica Serotype Dublin during Prosthetic Hip Joint Infection. Emerg Infect Dis. 2018;24(12):2360-3. https://doi.org/10.3201/eid2412.180214 PMID: 30457550

8. Selander RK, Smith NH, Li J, Beltran P, Ferris KE, Kopecko DJ, et al. Molecular evolutionary genetics of the cattle-adapted serovar Salmonella dublin. J Bacteriol. 1992;174(11):358792. https://doi.org/10.1128/jb.174.11.3587-3592.1992 PMID: 1592813

9. Werner SB, Humphrey GL, Kamei I. Association between raw milk and human Salmonella dublin infection. BMJ. 1979;2(6184):238-41. https://doi.org/10.1136/bmj.2.6184.238 PMID: 476402

10. Giron S, Le Hello S, Salah S, Mazur M, Lailler R, Barataud D, et al. Salmonella Dublin: what is its potential severity? Investigating a national foodborne outbreak of Salmonellosis associated with the consumption of raw milk cheese, France, August-September 2012. Poster session presented at: 6th International Symposium Salmonella and Salmonellosis (I3S); 2013 May 27-29; Saint-Malo, France.

11. Vignaud $M-L$, Cherchame E, Marault M, Chaing E, Le Hello S, Michel V, et al. MLVA for Salmonella enterica subsp. enterica Serovar Dublin: Development of a Method Suitable for InterLaboratory Surveillance and Application in the Context of a Raw Milk Cheese Outbreak in France in 2012. Front Microbiol. 2017;8:295. https://doi.org/10.3389/fmicb.2017.00295 PMID: 28289408

12. David JM, Sanders P, Bemrah N, Granier SA, Denis M, Weill FX, et al. Attribution of the French human Salmonellosis cases to the main food-sources according to the type of surveillance data. Prev Vet Med. 2013;110(1):12-27. https://doi. org/10.1016/j.prevetmed.2013.02.002 PMID: 23453456

13. Jones G, Le Hello S, Jourdan-da Silva N, Vaillant V, de Valk $\mathrm{H}$, Weill $\mathrm{F}$, et al. The French human Salmonella surveillance system: evaluation of timeliness of laboratory reporting and factors associated with delays, 2007 to 2011. Euro Surveill. 2014;19(1):20664. https://doi.org/10.2807/1560-7917. ES2014.19.1.20664 PMID: 24434174

14. Jourdan-Da Silva N, Le Hello S. [Salmonellosis in 2002-2010 in France: trends in human epidemiology, monophasic serotype emergence, main food implicated in the latest outbreaks]. Bulletin Epidémiologique Hebdomadaire Hors-série. 2012;2533. French.

15. Kjeldsen MK, Torpdahl M, Campos J, Pedersen K, Nielsen EM. Multiple-locus variable-number tandem repeat analysis of Salmonella enterica subsp. enterica serovar Dublin. J Appl 
Microbiol. 2014;116(4):1044-54. https://doi.org/10.1111/ jam.12441 PMID: 24517207

16. Mohammed M, Delappe N, O’Connor J, McKeown P, Garvey $\mathrm{P}$, Cormican M. Whole genome sequencing provides an unambiguous link between Salmonella Dublin outbreak strain and a historical isolate. Epidemiol Infect. 2016;144(3):576-81. https://doi.org/10.1017/S0950268815001636 PMID: 26165314

17. Ågren EC, Wahlström H, Vesterlund-Carlson C, Lahti E, Melin L, Söderlund R. Comparison of whole genome sequencing typing results and epidemiological contact information from outbreaks of Salmonella Dublin in Swedish cattle herds. Infect Ecol Epidemiol. 2016;6(1):31782. https://doi.org/10.3402/iee. v6.31782 PMID: 27396609

18. Gossner C, Le Hello S, De Jong B, Rolfhamre P, Faensen D, Weill FX, et al. Around the World in 1,475 Salmonella Geoserotypes. Emerg Infect Dis. 2016;22(7):1298-302. https://doi. org/10.3201/eid2207.141678

19. Fonteneau L, Jourdan Da Silva N, Fabre L, Ashton P, Torpdahl $M$, Müller L, et al. Multinational outbreak of travel-related Salmonella Chester infections in Europe, summers 2014 and 2015. Euro Surveill. 2017;22(7):30463. https://doi. org/10.2807/1560-7917.ES.2017.22.7.30463 PMID: 28230522

20. Langmead B, Salzberg SL. Fast gapped-read alignment with Bowtie 2. Nat Methods. 2012;9(4):357-9. https://doi. org/10.1038/nmeth.1923 PMID: 22388286

21. Treangen TJ, Ondov BD, Koren S, Phillippy AM. The Harvest suite for rapid core-genome alignment and visualization of thousands of intraspecific microbial genomes. Genome Biol. 2014;15(11):524. https://doi.org/10.1186/s13059-014-0524-X PMID: 25410596

22. Tamura K, Stecher G, Peterson D, Filipski A, Kumar S. MEGA6: Molecular Evolutionary Genetics Analysis version 6.o. Mol Biol Evol. 2013;30(12):2725-9. https://doi.org/10.1093/molbev/ mst197 PMID: 24132122

23. Letunic I, Bork P. Interactive tree of life (iTOL) v3: an online tool for the display and annotation of phylogenetic and other trees. Nucleic Acids Res. 2016;44(W1):W242-5. https://doi. org/10.1093/nar/gkw290 PMID: 27095192

24. Bachelerie P, Felten A, Vignaud ML, Glasset B, Feurer C, Lailler R, et al. MLVA Normalizer: Workflow for Normalization of MLVA Profiles and Data Exchange between Laboratories. J Proteomics Bioinform. 2016;9(2):25-7. https://doi.org/10.4172/ jpb.1000385

25. Debin M, Turbelin C, Blanchon T, Bonmarin I, Falchi A, Hanslik T, et al. Evaluating the feasibility and participants' representativeness of an online nationwide surveillance system for influenza in France. PLoS One. 2013;8(9):e73675. https://doi.org/10.1371/journal.pone.0073675 PMID: 24040020

26. Guerrisi C, Turbelin C, Blanchon T, Hanslik T, Bonmarin I, LevyBruhl D, et al. Participatory syndromic surveillance of influenza in Europe. J Infect Dis. 2016;214(suppl_4):S386-92. https:// doi.org/10.1093/infdis/jiw280 PMID: 28830105

27. Achtman M, Wain J, Weill FX, Nair S, Zhou Z, Sangal V, et al. S. Enterica MLST Study Group. Multilocus sequence typing as a replacement for serotyping in Salmonella enterica. PLoS Pathog. 2012;8(6):e1002776. https://doi.org/10.1371/journal. ppat.1002776 PMID: 22737074

28. Mook P, Kanagarajah S, Maguire H, Adak GK, Dabrera G, Waldram A, et al. Selection of population controls for a Salmonella case-control study in the UK using a market research panel and web-survey provides time and resource savings. Epidemiol Infect. 2016;144(6):1220-30. https://doi. org/10.1017/S0950268815002290 PMID: 26493476

29. Nielsen TD, Kudahl AB, Østergaard S, Nielsen LR. Gross margin losses due to Salmonella Dublin infection in Danish dairy cattle herds estimated by simulation modelling. Prev Vet Med. 2013;111(1-2):51-62. https://doi.org/10.1016/j. prevetmed.2013.03.011 PMID: 23628337

30. Spier SJ, Smith BP, Cullor JS, Olander HJ, Roden LD, Dilling GW. Persistent experimental Salmonella dublin intramammary infection in dairy cows. J Vet Intern Med. 1991;5(6):341-50. https://doi.org/10.1111/j.1939-1676.1991.tbo3148.x PMID: 1779428

31. Uzzau S, Brown DJ, Wallis T, Rubino S, Leori G, Bernard $\mathrm{S}$, et al. Host adapted serotypes of Salmonella enterica. Epidemiol Infect. 2000;125(2):229-55. https://doi.org/10.1017/ So950268899004379 PMID: 11117946 may share and adapt the material, but must give appropriate credit to the source, provide a link to the licence, and indicate if changes were made.

This article is copyright of the authors or their affiliated institutions, 2019.

\section{License and copyright}

This is an open-access article distributed under the terms of the Creative Commons Attribution (CC BY 4.0) Licence. You 